\title{
Combined sciatic-psoas compartment nerve block in a patient with multiple myeloma
}

\author{
Orhan Binici* and Fethi Akyol \\ Erżincan University Faculty of Medicine Gazi Mengücek Education and Research Hospital, Anesthesiology and \\ Reanimation, Erzincan, Turkey
}

\begin{abstract}
New techniques for the regional administration of anesthesia are being developed every day. Peripheral nerve blocks affect only minimally a patient's hemodynamics, and may be the ideal choice in high-risk patients who may be intolerant to even a minor decrease in hemodynamic response. In this case report, the use of a combined sciatic-psoas compartment nerve block for a lower extremity surgery in a high-risk patient with multiple myeloma, acute renal failure and ASA III risk is addressed.
\end{abstract}

Key Words: Peripheral nerve blocks, multiple myeloma, sciatic nerve block

\section{Introduction}

Multiple Myeloma (MM) is a hematological malignant tumor that is made up of atypical plasma cells originating from bone marrow, and is seen especially in adulthood. The most frequently affected bones are, in descending order, vertebra, skull, pelvis, costae, scapula, humerus and femur (1-2). The risk factors that must be considered in cases of multiple myeloma are renal failure, bleeding diathesis, increased predisposition to infections, hyperviscosity syndrome, anemia and hypercalcemia (3). The anesthetic management of a patient, with the intention being to decrease the already increased risk associated with anesthesia in the presence of MM to a minimum is presented in this case report.

\section{Case report}

A psoas compartment block and an ultrasoundguided sciatic block was planned for the anesthetic management of a 44 year-old ASA III patient with a fractured femur, accompanied by diagnoses of MM and acute renal failure. The patient was undergoing dialysis every three days and had coarse bilateral respiratory sounds with no abnormality in vital signs. The post-dialysis laboratory results of the patient were as follows: Urea: $121 \mathrm{mg} / \mathrm{dL}$, Creatinine: $5.08 \mathrm{mg} / \mathrm{dL}$, Albumin: $1.8 \mathrm{~g} / \mathrm{dL}$, PT: 17.5 sec., INR: 1.45 and aPTT: 36.3 sec. A psoas compartment block and ultrasound-accompanied sciatic block were planned for the patient, who had no pathology other than those presented here. The patient was monitored in the operating room and intravenous midazolam was administered in a dose of 0.15 $\mathrm{mg} / \mathrm{kg}$. The psoas compartment block was achieved through the administration of $25 \mathrm{~mL}$ of LA (15 mL 0.5\% levobupivacaine $+10 \mathrm{~mL} 2 \%$ lidocaine) with the patient in the lateral decubitus position and using the neurostimulation technique between the L3-4 paravertebral space when a motor response against a $0.5 \mathrm{~mA}$ current was received (Figure 1). A subsequent sciatic nerve image was obtained using the convex probe of the ultrasound in the gluteal region and $20 \mathrm{~mL} \mathrm{LA} \mathrm{(10}$

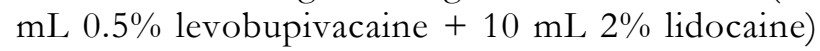
was injected around the sciatic nerve (Figure 2). Sensorial and motor block developed 20 minutes after the procedure and vital signs were stable during the entire operation. No complications were encountered during or after the operation, which lasted 2 hours and 30 minutes, and analgesia lasted for six hours after the operation. The postoperative course was unproblematic, and the patient was discharged on the postoperative $4^{\text {th }}$ day.

\section{Discussion}

Peripheral nerve blocks are easily applied in many surgical procedures involving the upper and lower extremities. The frequency of deep vein thrombosis, pulmonary embolism, transfusion requirement, pneumonia, respiratory depression, 


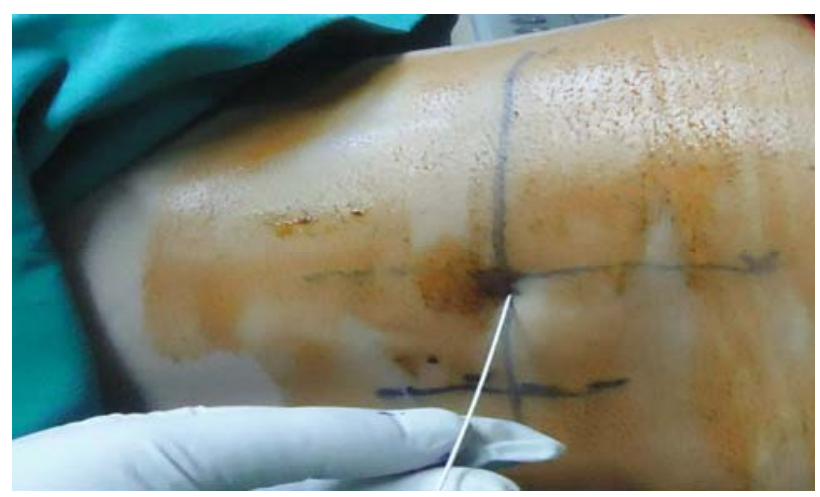

Fig. 1. Lateral decubitus position psoas compartment block.

myocardial infarct and renal failure are decreased significantly in cases in which peripheral nerve blocks are applied (4-5). Peripheral nerve blocks affect the hemodynamics only minimally, and are probably the most suitable choice in high-risk patients who are unable to tolerate even a slight decrease in hemodynamic response (6). Naja et al. (7) made a comparison between a combined sciatic-paravertebral block and general anesthesia in hip fracture surgery in elderly patients, and reported a decreased incidence of hypotension and a reduced requirement for postoperative intensive care in the combined sciatic-paravertebral block group.

The most important advantages of peripheral nerve blocks over general anesthesia and central blocks are the decreased effects on respiration and hemodynamics (such as sympathetic block, hypotension and bradycardia), the decreased risk of complications of anesthesia and shorter duration of recovery (6-8). Fanelli et al. (8) compared the hemodynamic changes of patients who underwent combined sciatic-femoral blocks and unilateral spinal anesthesia. The mean arterial pressure and cardiac index of the patients decreased by 15 percent and 15-20 percent respectively in the group who underwent spinal anesthesia, while these measures were found to be unchanged in the group who underwent a sciaticfemoral nerve block. The development of an epidural hematoma approximately two months after the procedure was reported in a patient with a prior diagnosis of $\mathrm{MM}$ in the spinal anesthesia group through the L2-3 level (9). A cerebral stroke due to hypertension following the development of intraoperative hypotension was developed in a case with MM who underwent a hip prosthesis operation with epidural anesthesia. In this case, MM was reported as having contributed to the development of a stroke with

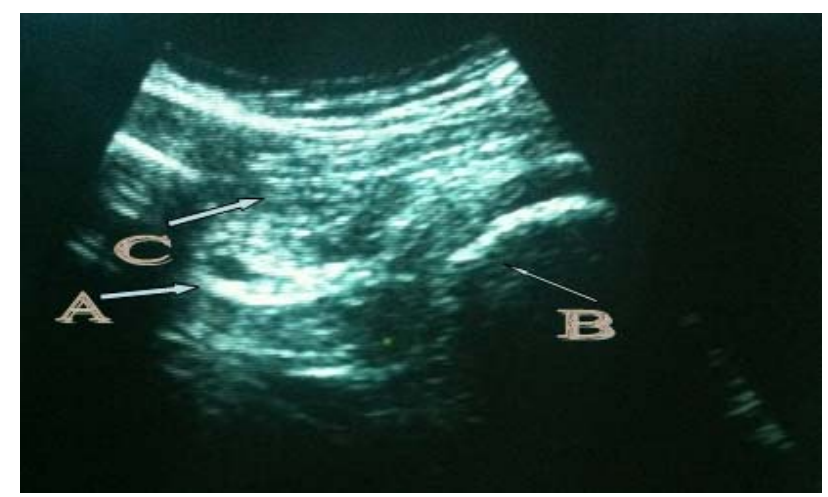

Fig. 2. A. Sciatic nerve B: Tuber Isciyatikum C: Gluteus Maximus.

predisposing hyperviscosity (10). In the case presented in this report, general anesthesia was not advised since the levels of creatinine and urea were high as a result of acute renal failure, and because coarse bilateral lung sounds were present. A central block was also ruled out so as to decrease the rate of complications related to the high PT and INR levels in the patient.

In conclusion, anesthesiologists should select the most appropriate method to decrease the possibility of complications in high-risk patients to a minimum. In this regard, a sciatic-psoas compartment nerve block is considered to be a good alternative to other methods of anesthesia (as long as the location and duration of surgery is appropriate) when planning the anesthetic management of high-risk patients with multiple myeloma and additional problems, so as to decrease the rate of complications to a minimal rate.

\section{References}

1. Lae ME, Vencio EF, Inwards CY, Unni KK, Nascimento AG. Myeloma of the jaw bones: a clinicopathologic study of 33 cases. Head Neck 2003; 25: 373-381.

2. Miles DA, Kaugars GE, van Dis M, Lovas LGL. Oral and maxillofacial radiology radiologic/ pathologic correlations. Philadelphia: WB Saunders Co 1991; 101-113.

3. Wake M, Matsushita M, Hirai Y. Anesthetic experiences in 3 patients with multiple myeloma. Masui 1995; 44: 1282-1284.

4. In: Morgan GE, Mikhail MS, Murray MJ, Larson CP, eds. Clinical anesthesiology. 3rd ed. New York: McGraw-Hill Companies 2002; 283-285

5. Urwin SC, Parker MJ, Griffiths R. General versus regional anaesthesia for hip fracture surgery: a meta-analysis of randomized trials. $\mathrm{Br} \mathrm{J}$ Anaesth 2000; 84: 450-4555. 
6. Chia N, Low TC, Poon KH. Peripheral nerve blocks for lower limb surgery--a choice anaesthetic technique for patientswith a recent myocardial infarction? Singapore Med J 2002; 43: 583-586.

7. Naja Z, Hassan MJ, Khatib H, Ziade MF, Lonnqvist PA. Combined sciatic-paravertebral nerve block ve general anaesthesia for fractured hip of the elderly. Middle East J Anesthesiol 2000; 15: 559-568.

8. Fanelli G, Casati A, Aldegheri G, et al. Cardiovascular effects of two different regional anaesthetic techniques for unilateral leg surgery. Acta Anaesthesiol Scand 1998; 42: 80-84.

9. Tank S, Rempf C, Kothe R, Gottschalk A. An undiagnosed plasma cell myeloma. Complication after performing spinal anesthesia. Anaesthesist 2007; 56: 236-238.

10. Wang CJ, Cheng KI, Soo LY, Tang CS. Intraoperative stroke under epidural anesthesia for bipolar hemiarthroplasty in a patient with multiple myeloma: a case report. Kaohsiung J Med Sci 2001; 17: 55-59. 